\title{
MISSING COPPER T WITH UTERINE PERFORATION: TWO CASE REPORTS
}

Savitha H. C1 , Sanjay Kumar C2, Gopala Krishna K. H³, Deepthi H. R ${ }^{4}$

\section{HOW TO CITE THIS ARTICLE:}

Savitha H. C, Sanjay Kumar C, Gopala Krishna K. H, Deepthi H. R. "Missing Copper T with Uterine Perforation: Two Case Reports". Journal of Evolution of Medical and Dental Sciences 2014; Vol. 3, Issue 14, April 07;

Page: 3640-3643, DOI: 10.14260/jemds/2014/2334

ABSTRACT: Intrauterine devices are currently one of the most popular reversible contraception methods used worldwide. IUCD is common method of contraception among women because of its low cost and high efficacy. Though relatively safe, it may cause dangerous complications like uterine perforation. We present two cases of missing IUCDs, in which there was IUCD migration into the peritoneal cavity after perforating the uterus adherent to the serosa of the bladder and omentum. In the other case, IUCD was seen half-way perforating the uterus.

KEYWORDS: IUCD, perforation, uterus, bladder.

INTRODUCTION: IUCD is the second most common and most effective contraception adopted worldwide since $1965 .{ }^{1}$ In developing countries, it is the most popular reversible method of long term contraception due to easy availability, low cost and reasonably good effects. ${ }^{2,3}$ It can be used for long term and is highly effective. IUCD does not interfere with lactation and because of this, many lactating women prefer IUCDs for contraception. Although relatively safe, it can be associated with problems like irregular menses, infections, and rarely it can lead on to uterine perforation and associated complications.

We are reporting two different cases of missing copper $\mathrm{T}$ with uterine perforation which were admitted and operated at district hospital, Mandya institute of medical sciences, Mandya.

CASE 1: A 22 year old lady presented with amenorrhea since 1 month 12 days, lower abdominal pain since 2 days, spotting per vagina and fever since 1 day. She was G3P2L2 delivered vaginally 1 year 2 months back and IUCD insertion was done 8 months back at PHC during which she had lactational amenorrhea.

On examination, her general condition was good, vital signs were normal. Abdomen was soft, tenderness present in the suprapubic, umbilical region and both iliac fossa. On speculum examination, IUCD thread was not seen, serosanguinous discharge was present, and uterus was enlarged to 6 to 8 weeks size with forniceal tenderness on per vaginal examination.

Urine pregnancy test was weakly positive. Ultrasound scanning revealed bulky uterus with retained products of conception, with $\mathrm{d} / \mathrm{d}$ of displaced IUCD/ectopic pregnancy/ inflammatory tubo ovarian mass on right side.

Patient was posted for emergency laparotomy after doing relevant investigations. Per operatively, right ovary and right fallopian tube was normal, left ovary and tube was inflamed.

Omental adhesions present on the left anterior uterine wall (site of perforation) and posterior bladder wall on left side (Figure 1A). Omental adhesions released, IUCD released from the serosa of the posterior bladder wall (Figure 1B), serosa of the bladder was sutured in 2 layers with 2-0 vicryl. 
Dilatation and evacuation was done. Urine was clear at the end of the procedure; bladder was catheterized for 14 days. Post-operative period was uneventful. Patient was discharged on $14^{\text {th }}$ day after removal of the catheter.

CASE 2: A 21 year old lady referred from PHC, came with pain abdomen since 5 days. She was P1L1 delivered vaginally 3 years back, IUCD insertion was done 2 months following the delivery. Her general physical examination and systemic examination were within normal limits. On per speculum examination, IUCD thread was not seen and forniceal tenderness was present on bimanual examination. Ultrasound revealed portion of the IUCD perforating through the fundus, other end of the IUCD was seen in the fundal aspect of endometrial cavity.

Under ultrasound guidance removal of IUCD was attempted, but failed. Laparotomy was done which revealed fundal perforation on right side (Figure 2B), through which IUCD was perforating half- way out, and omental adhesions were noted (Figure 2A). Both ovaries and tubes were normal. IUCD was removed (Figure 2C) and abdomen was closed in layers. Postoperative period was uneventful; patient was discharged on $7^{\text {th }}$ day.

DISCUSSION: Perforation of the uterus by an IUCD was first described in 1930 by Murphy and Andrews independently. ${ }^{4}$ The incidence of perforation is 0.1 to 3 per 1000 insertions. ${ }^{5}$ Uterine perforation almost always occurs during insertion of IUCD and its incidence is related to the timing of insertion, type of device, the anatomy of the uterus and cervix, and most importantly the skill and experience of the person performing the insertion and also faulty insertion technique, soft uterine wall, recent pregnancy, abortion and previous uterine scar. ${ }^{6}$

Secondary perforation can occur by slow migration through the muscular wall of the uterus which can be augmented by spontaneous uterine contractions and urinary bladder contractions. ${ }^{7}$ Migrated IUCD remain unnoticed for long and may not be discovered until it is found to be missing. ${ }^{8}$

All migrated IUCDs must be removed. An IUCD in peritoneal cavity can cause bowel perforation, bowel obstruction and fistula formation. Perforation of bowel can lead to peritonitis and stricture. Presentation of symptoms of bowel perforation can take upto 6 months to 16 years to occur. ${ }^{9,10}$

Sonography with transvaginal and transabdominal approaches is a useful method to detect IUCD migration. In some cases computed tomography is needed for diagnosis. ${ }^{11}$

CONCLUSION: Every case of a missing IUCD, even with presence of pregnancy must be investigated carefully for uterine perforation. The possibility of IUCD migration into other intra-abdominal organs is always possible. Prevention of perforation can be avoided by correct insertion by experienced person, regular follow up after insertion. If any symptoms of perforation occurs, ultrasound or pelvic radiography should be done.

\section{REFERENCES:}

1. Farooq F, Afridi Z, Farooq MA, Ishtiaq Ahmad Qureshi IA. Urological complications of intrauterine contraceptive device. JPMI 2007; 21:260-65.

2. Barsual M, Sharma N, Sangwan K. Three hundred and twenty four cases of misplaced IUCD - a five years study. Trop Doct.2003; 33: 11-12. 
3. Zafar M, Murtaza N and Saeed S. Two displaced intrauterine contraceptive devices (Copper-T). JCPSP 2004; 14: 427-29.

4. Thomalla V. Perforation of urinary bladder by intrauterine device. J Urology. 1986; 27: 260-64.

5. Zakin D, Stern WZ, Rosenblatt R. Complete and partial uterine perforation and embedding following insertion of intrauterine devices: I Classification, complications, mechanism, incidence and missing string. Obstet Gynaecol Surv 1981; 36:335-53.

6. Boyon C, Giraudet G, Guerin Du Masgenet B, Lucot JP, Goeusse P, Vinatier D. Diagnosis and management of uterine perforations after intrauterine device insertion: A report of 11 cases. Gynecol Obstet Fertil, 2012 July [E pub ahead of print].

7. Singh I. Intravesical $\mathrm{Cu}-\mathrm{T}$ migration: an atypical and infrequent cause of vesical calculus. Int Urol Nephrol. 2007; 39: 457-59.

8. Eke N, Okpani AO. Extrauterine translocated contraceptive device: a presentation of five cases and revisit of enigmatic issues of iatrogenic perforation and migration. Afr J Reprod Health.2003; 7:117-23.

9. Nceboz US, Ozcakir HT, Uyar Y, Caglar H. Migration of an intrauterine contraceptive device to the sigmoid colon: A case report. Eur J Contracept Reprod Health Care.2003; 8:229-32.

10. Istanbulluoglu MO, Ozcimen EE, Ozturk B, Uckuyu A, Cicek T, Gonen M. Bladder perforation related to intrauterine device. J Chin Med Assoc.2008; 71: 207-209.

11. El-hefnawy AS, El-nahas AR, Osman Y, et al. Urinary complications of migrated intrauterine contraceptive device. Int Urogynecol J 2008; 19:241-45.

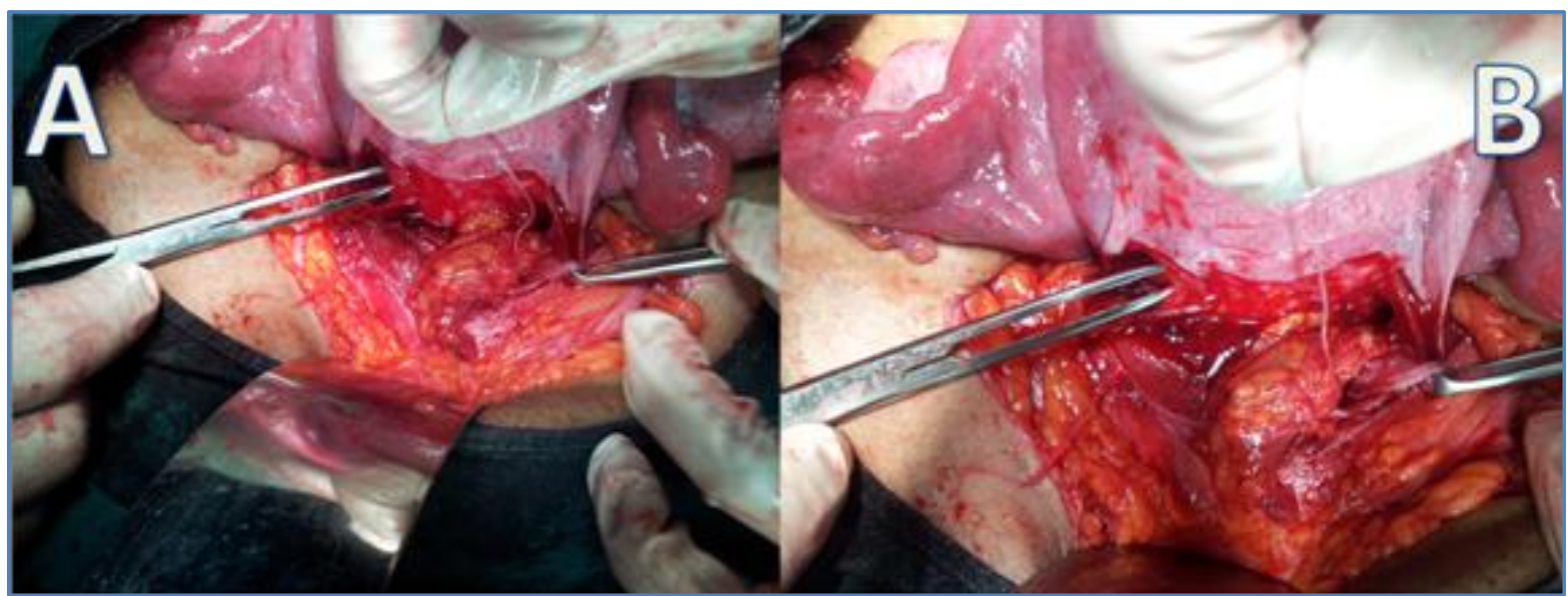

Figure 1A

Figure 1B

Figure 1: A) Cu-T string seen along with omental adhesions between left anterior uterine wall (site of perforation) and posterior surface of bladder. B) Cu-T string seen adherent to serosal surface of bladder after releasing the adhesions. 


\section{CASE REPORT}

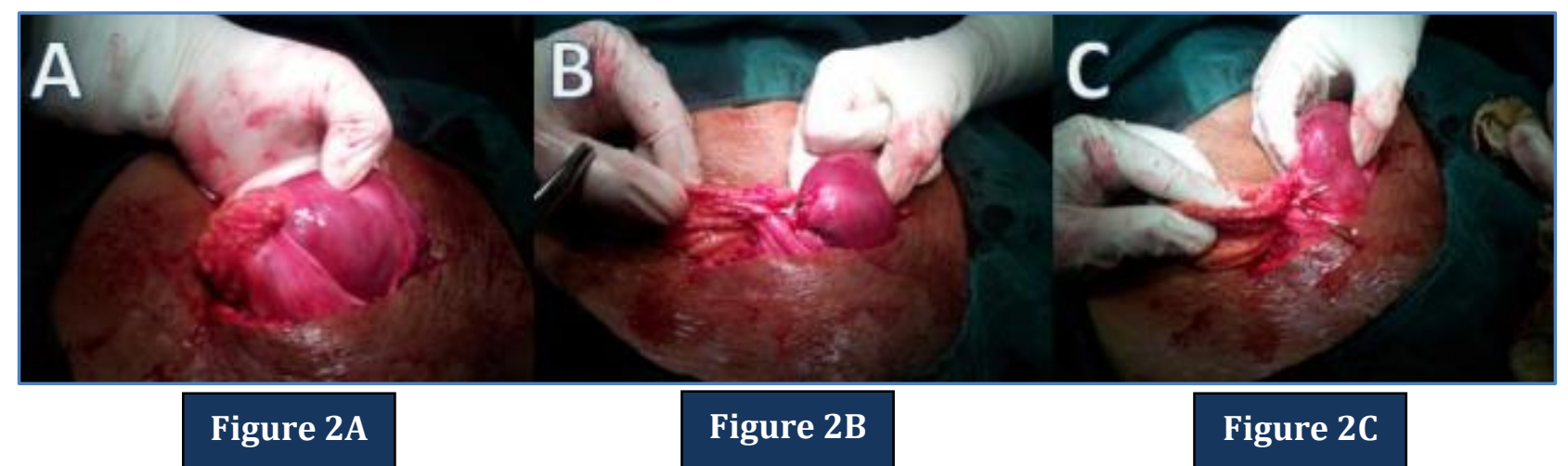

Figure 2: A) Cu-T seen with omental adhesions to the fundal aspect of the uterus. B) $\mathrm{Cu}-\mathrm{T}$ seen perforating the fundus of the uterus and adherent to the omentum. $\mathrm{C}$ ) $\mathrm{Cu}$-T seen during the process of removal.

\section{AUTHORS:}

1. Savitha H. C.

2. Sanjay Kumar C.

3. Gopala Krishna K. H.

4. Deepthi H. R.

\section{PARTICULARS OF CONTRIBUTORS:}

1. Associate Professor, Department of OBG, MIMS.

2. Assistant Professor, Department of OBG, MIMS.

3. Assistant Professor, Department of Surgery, MIMS.

4. Junior Resident, Department of OBG, MIMS.

\section{NAME ADDRESS EMAIL ID OF THE} CORRESPONDING AUTHOR:

Dr. Savitha H. C, Associate Professor, OBG, MIMS, Mandya.

E-mail: drhcsavithamohan@gmail.com

Date of Submission: 06/03/2014. Date of Peer Review: 07/03/2014. Date of Acceptance: 19/03/2014. Date of Publishing: 02/04/2014. 